\title{
Monitoring of the Patient with Toxic Epidermal Necrolysis in the Intensive Care Unit
}



Toksik epidermal nekroliz (TEN) genellikle ilaçlara karşı gelişen, akut seyirli, deri ve mukozaları tutan ve şiddetli döküntü ile seyreden bir hastalıktır. Keratinositlerin yüzeylerinde gösterdikleri antijenler nedeniyle bu hücrelere karşı gelişen sitotoksik immün reaksiyon sonucunda hastalık ortaya çıkar. Hastalığın şiddeti ve verilen sağlık hizmetinin kalitesi hastalığın prognozunu ve doğal olarak da mortalite oranını belirler. Tedavinin en önemli basamakları; erken tanı ve şüpheli ilaç ya da ilaçların hemen kesilmesidir. Elli dokuz yaşında, TEN tanılı, kadın hastanın tedavisi yoğun bakımda başarıyla yönetildi.

Kabul tarihi: 16.10 .2019

Yayın tarihi: 31.12 .2019

Anahtar kelimeler: toksik epidermal nekroliz, yoğun bakım, SCORTEN mortalite skalası

\section{ABSTRACT}

Toxic epidermal necrolysis (TEN) is a disease that usually develops against drugs, has an acute course, involves the skin and mucous membranes, and is accompanied by severe rash. The disease severity, and quality of health care provided determines the prognosis of the disease and naturally the mortality rate. The most important steps of treatment are early diagnosis and immediate discontinuation of suspected drug(s). A 59-year-old female patient with TEN was managed successfully in the intensive care unit.

Mine Alttnkaya Çavuş Kayseri Şehir Hastanesi Kayseri - Türkiye minealtinkaya@yahoo.com ORCID: 0000-0003-2584-0463

Ş. G. Bektaş 0000-0001-6057-732X Ankara Sehir Hastanesi Ankara - Türkiye

K. Özyurt 0000-0002-6913-8310 Kayseri Şehir Hastanesi Kayseri - Türkiye

Keywords: toxic epidermal necrolysis, intensive care, SCORTEN mortality scale

\section{GiRiş}

Toksik epidermal nekroliz (TEN) genellikle ilaçlara karşı gelişen, akut seyirli, deri ve mukozaları tutan ve şiddetli döküntü ile seyreden bir hastalıktır. Bugün Steven-Johnson sendromu (SJS) ve toksik epidermal nekroliz birbirinin devamı olan ve ilaç reaksiyonları başlığı altında tanımlanan bir grup hastalık olduğu, eritema multiforme (EM)'nin ise Herpes simplex virus gibi farklı etkenler ve farklı klinik bulgularla ortaya çıkan ayrı bir hastalık olduğu bilinmektedir. SJS ve TEN'in ayırımındaki temel belirteç, hastalığa katılan vücut yüzeyi oranıdır (epidermisin ayrışma veya potansiyel ayrışma yüzdesi). Eğer tutulum \%10'un altındaysa SJS, \%30'un üzerindeyse TEN olarak kabul edilir. Yüzde 10-30 oranında tutulum ise SJS/TEN geçiş olguları (SJS/TEN overlap) olarak değerlendirilir ${ }^{[1-3]}$. TEN erişkinlerde daha sıktır; hastalığın sıklığı yaşla artış gösterir, her iki cinsiyette benzer oranda görülür ${ }^{[4-6]}$.

Keratinositlerin yüzeylerinde gösterdikleri antijenler nedeniyle bu hücrelere karşı gelişen sitotoksik immün reaksiyon sonucunda hastalık ortaya çıkar. Büyük olasılıkla ilaçlar ya da onların metabolitleri hapten rolü görerek keratinositlerin yüzeyine bağlanmakta

(C) Telif hakkı Göğüs Kalp Damar Anestezi ve Yoğun Bakım Derneği'ne aittir. Logos Tıp Yayıncılık tarafindan yayınlanmaktadır Bu dergide yayınlanan bütün makaleler Creative Commons Atff-Gayri Ticari 4.0 Uluslararası Lisansı ile lisanslanmıştı.

(c) Copyright The Society of Thoracic Cardio-Vascular Anaesthesia and Intensive Care. This journal published by Logos Medical Publishing. Licenced by Creative Commons Attribution-NonCommercial 4.0 International (CC BY-NC 4.0) 
Tablo 1. Scorten mortalite skalası ${ }^{[4]}$.

Faktörleri

Yaş>40

$\mathrm{KAH}=120 \mathrm{dk}$

Kanser veya hematolojik malignite

Tutulan vücut yüzeyi $>\% 10$

Kan üre nitrojen $>10 \mathrm{mmol} / \mathrm{L}(28 \mathrm{mg} / \mathrm{dL})$

Serum bikarbonat seviyesi $<20 \mathrm{~mL} / \mathrm{L}(20 \mathrm{meq} / \mathrm{L})$

Kan glikoz düzeyi $>14 \mathrm{mmol} / \mathrm{L}(252 \mathrm{mg} / \mathrm{dL}$ )
Mortalite oranları

$0-1$ faktör $=\% 3$

2 faktör=\%12

3 faktör $=\% 35$

4 faktör $=\% 58$

5 veya daha fazla faktör $=\% 90$

KAH: Kalp atım hızı

ve onların antijenik hâle gelmelerine neden olmaktadır ${ }^{[7]}$.

Hastalığın şiddeti ve verilen sağlık hizmetinin kalitesi hastalığın prognozunu ve doğal olarak da mortalite oranını belirler. Mortalite oranı TEN' de \%30 kadardır ${ }^{[8]}$. Sepsis ve çoklu organ yetmezliği en önemli ölüm nedenleridir. Pulmoner emboli, akut solunum sıkıntısı sendromu, kalp yetmezliği, gastrointestinal kanama, sıvı ve elektrolit düzensizliği ile böbrek yetmezliği diğer ölüm nedenleridir. Bastuji-Garin ve ark. ${ }^{[9]}$ tarafından TEN için geliştirilen SCORTEN ölçeği hastalığın şiddetini ve buna bağlı olarak da mortalite oranını tahmin etmede sıklıkla kullanılmaktadır (Tablo 1). Mortaliteyi artıran diğer faktörler; trombositopeni, lökopeni, hastaneye geç başvuru başvuru öncesi antibiyotik veya kortikosteroid kullanımı, sorumlu ilacın yarılanma ömrünün uzun olması ve şiddetli tutulumlularda yoğun bakım ünitesine geç transferdir ${ }^{[10-13]}$. Son yıllarda özellikle TEN'li hastaların öncelikle yanık merkezinde, olası değilse yoğun bakım ünitelerinde takibi daha çok kabul görmeye başlamıştır. Epidermal ayrışma oranı \%35'ten daha az olanlarda yüksek olanlara göre mortalite oranı belirgin şekilde düşüktür. Yine yaş ve BUN yüksekliği gibi ek faktörler mortalite hızını belirgin şekilde arttırmaktadır ${ }^{[14]}$.

Tedavinin en önemli basamakları; erken tanı ve kuşkulu ilaç ya da ilaçların hemen kesilmesidir. En kuşku- lu ilaç döküntüden önceki 3 hafta içinde başlanandır [12]. Yoğun bakımda uygulanan destek tedavisinin etkin olması çok önemlidir. Sıvı, elektrolit ve protein dengesi iyi izlenmeli ve dikkatlice düzenlenmelidir. Hastaya yüksek kalori ve protein içeren diyetler önerilir ${ }^{[15]}$. Dış ortam ısısı $30-32^{\circ} \mathrm{C}$ olmalıdır. ikincil infeksiyon ve sepsis riski nedeniyle dikkatli olunmalı, uygun steril koşullar sağlanmalıdır. Doğrudan antibiyotik başlanması önerilmez. Göz bakımı; erken dönemde yerel nemlendiriciler, antibiyotikler ve steroitli göz damlaları ile yapılmalıdır. Pozisyonel drenaj ve destekleyici pulmoner bakım, ağrı ve anksiyetenin kontrolü, stres ülseri gelişiminin önlenmesi önemlidir. Tromboemboli riski gözetilerek uygun heparinizasyon sağlanmalıdır. Epidermis ayrıldıktan sonra erode alanlar yapay membranlarla veya biyolojik örtülerle kapatılabilir. Bu uygulama ağrıyı azaltırken, epitelizasyonu hızlandırır ve infeksiyon riskini azaltır ${ }^{[15]}$. Sistemik tedavide çok sayıda seçenek kullanılmasına rağmen, etkinliği kanıtlanmış bir ilaç yoktur ${ }^{[16]}$. Kortikosteroidlerin tedavideki yeri hâlen tartışmalıdır. Bazı yazarlar olayın hemen başlangıcında, kısa süreli ve yüksek dozlarda kullanılan kortikosteroidlerin (100-1000 mg/g dozunda 3-4 gün süreyle, intravenöz metil prednisolon veya deksametazon $1,5 \mathrm{mg} /$ $\mathrm{kg} / \mathrm{g}, 3$ gün) etkili olabileceği üzerinde durmaktadır [17]. Erken başlanan kortikosteroid tedavisinin sorumlu ilacın hemen kesilmesi yanında tamamlayıcı bir tedavi yöntemi olabileceğini düşündürmektedir ${ }^{[6]}$. Son yıllarda oldukça iyi sonuçlar bildirilen bir diğer 
uygulama ise intravenöz immünglobulin-G (iviG)'nin, 0,2-0,75 g/kg dozunda ardışık olarak 4 gün kullanımıdır. Deri döküntüsünden itibaren ilk 4 günde tedavi alan hastalarda, ilaç hastalığın ilerlemesini hızla durdurmakta ve epitelizasyonu hızlandırmaktadır [18]. Toplam doz olarak 3-4 g/kg'lık dozlar daha düşük dozlara göre etkili bulunmuştur ${ }^{[19]}$.

\section{OLGU}

Elli dokuz yaşında kadın hasta, hastaneye başvurusundan 2 gün önce başlayan vücutta yaygın makulo- papüler döküntüsü mevcut. Üç hafta önce sol koldan osteomyelit nedenli opere olmuş. Uzun süreli (3 hafta) trimetoprim-sulfametoksazol kullanımı sonrası boyundan başlayıp vücuda yayılan makulopapüler döküntüler, oral mukozada tutulum, konjuktivada eritem (Resim 1) ve yoğun sekresyon meydana gelmesi üzerine TEN tanısı ile hastaneye yatışı yapıldı. Bir gün sonra yer yer erode alanlar ve büller gözlendi. Bilinen hipertansiyonu olan hasta anjiyotensin reseptör blokeri kullanmaktaydı.

Dermatolojik muayenesinde vücutta yaygın makulo-

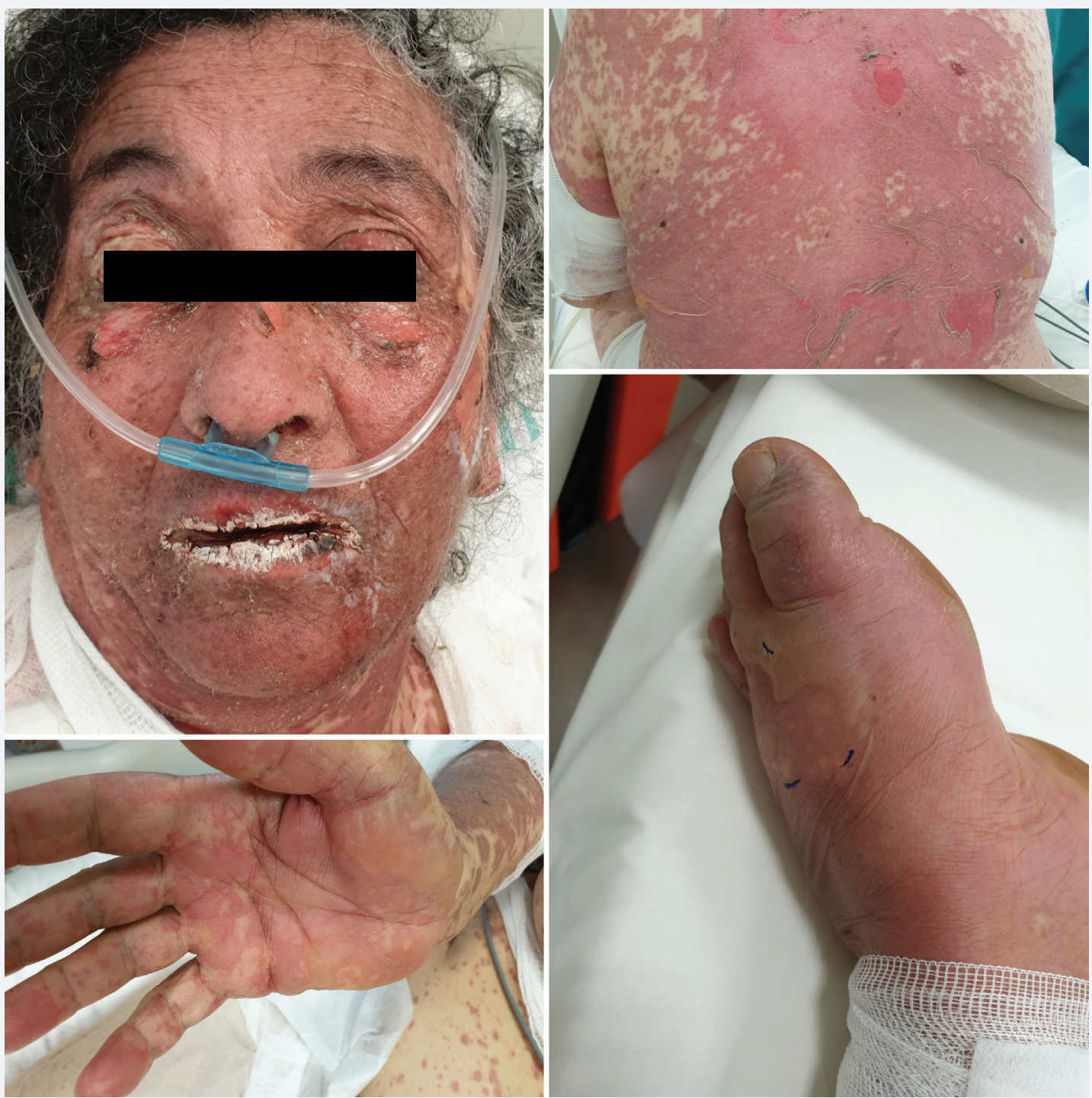

Resim 1. Boyundan başlayıp vücuda yayılan makulopapüler döküntüler, oral mukozada tutulum, konjuktivada eritem. 
papüler döküntü oral mukoza ve göz tutulumu mevcuttu. Ayrıca ayak, kol, boyun ve sırtta büller gözlendi. Hastanın saatler içerisinde lezyonlarında artış olması ve vücut yüzeyinin \%40’ına ulaşması ile yoğun bakımda tek kişilik izole odaya nakli gerçekleştirildi. Tedavi için 2 g/kg IVIG planlandı, bu doz 5 güne bölünerek verildi. Prednol 40 mgx2, n-asetil sistein 600 mgx3, proton pompa inhibitörü $40 \mathrm{mg}$, DMAH (düşük molekül ağırlıklı heparin) 0.4 iü olacak şekilde tedavisi planlandı. İnfeksiyon hastalıkları tarafından teikoplanin ve ertapenem başlandı. Ağız mukozasında oluşan yaygın lezyonlar nedeniyle oral alımı durduruldu. Yaygın deri lezyonları nedeniyle damar yolu açamadı- ğımız ve oral yoldan besleyemediğimiz hastaya santral katater takıldı. Total parenteral nutrisyon (TPN), günlük $25 \mathrm{kcal} / \mathrm{kg}$ olacak şekilde planlandı. Ağız mukozasındaki lezyonlar için klorheksidinli gargara ve sodyum bikarbonatlı ağız pansumanı, göz tutulumu moksifloksasin damla, hyaluronik asitli damla, refresh ve basitrasin-neomisin göz pomadı uygulandı. Intravenöz sıvıları hastanın insensible kayıpları göz önünde bulunarak aldığı-çıkardığı +500, +1000 olacak şekilde düzenlendi. İdrar çıkışı $1 \mathrm{~mL} / \mathrm{kg} / \mathrm{saat}$ olacak şekilde sıvı resüsitasyonu planlandı.

Tüm laboratuvar verileri (biyokimya, tam kan ve koa-



Resim 2. Hastanın tüm lezyonları TEN’e spesifik izler bırakarak geriledi. 
gülasyon) normal sınırlarda olan hastanın taburcu olana kadar hiçbir parametresinde bozulma gözlenmedi. Hastanın bülleri günlük aspire edilip serum fizyolojik ile silinip antiseptik steril yara pansumanı ürünü ile pansuman yapıldı. Yoğun bakım yatışının 8 . günü oral alımı açılan hasta, yatışının 12. günü oral alımının ve genel durumunun iyileşmesi üzerine dermatoloji servisine nakil edildi. Takiplerde TPN kesildi. Rejim 2, yüksek proteinli beslenme planlandı. Yatışının 14. günü prednol 60 mg'a düşüldü, antihistaminik eklendi. Prednol azaltılarak kesildi. Hatanın tüm lezyonları TEN'e spesifik izler bırakarak geriledi (Resim 2). Yatışının 26. günü hasta infeksiyon hastaIıklarına kronik osteomiyelit tedavisi için yönlendirilerek taburcu edildi.

\section{TARTIŞMA}

TEN tanısı ile takip edilen hastaların yarısında prodromal belirtiler vardır (ateş, baş ağrısı, rinit, halsizlik, boğaz ağrısı, gözlerde kaşıntı, ağrı vb.). Üst solunum yolu infeksiyonu ile karışabilen bu belirtiler mukozal tutuluma işaret etmektedir. Ağız, göz, burun ve anogenital mukoza belirtileri sıklıkla hastalığın habercisidir. Kaşıntı, yanma ve ağrı yakınması bulber konjonktiva, dudak ve yanak mukozası tutulumunun ilk belirtileri olabilir. Bunu izleyerek eritem, ödem ve vezikül/bül gelişir. Özellikle ağızda büllerin açılmasıyla yaygın, hemorajik görünümde kırmızı erode alanlar ortaya çıkar. Dudaklar karakteristik olarak aşırı miktarda ve hemorajik özellikte krutlarla kaplıdır. Hastaların neredeyse tamamında ağız ve dudakların vermilyon sınırı tutulur. Lezyonlar ağrılıdır; soluma ve yeme, içme işlevini engelleyebilir. Gözlerde, kızarıklık, kemozis, ağrıı veziküller, erozyonlar, çift taraflı lakrimasyon ve daha nadiren korneal ülser, üveit ve hatta panoftalmi gelişebilir. Burun tıkanıklığı, kabuklanma ve kanama burun mukozası tutulumu sonucu gelişebilir. Genital bölgedeki ağrılı hemorajik büller ve erode alanlar üriner retansiyona yol açabilir. Kadınlarda son derece şiddetli vajinal ağrı gözlenebilir. Anal erozyon daha nadir ortaya çıkar ${ }^{[3,20,21]}$. Bizim olgumuzda da; ağız, göz, burun ve anogenital mukoza tutulumları mevcuttu. TEN olgularının çoğunluğu- nun, genellikle ilaç tedavisi başladıktan sonra 1-3 hafta içinde meydana geldiği, ancak bazı olgularda tedavi başlangıcından 8 hafta sonraya kadar görülebildiği bazı yazarlarca belirtilmektedir ${ }^{[22]}$. Olgumuzda antibiyoterapinin 3. haftasında döküntülü lezyonlar görülmeye başlanmıştı. TEN'li hastalarda gözde kornea erozyonları, ülserleri ve akut konjonktivit şeklinde tutulumlar olmaktadır [22]. TEN'de tipik olarak daha az agresif sıvı replasmanı gerektiren daha az ciddi mikrovasküler hasar mevcut olduğundan ciddi yanıklarda kullanılan yoğun sıvı resüsitasyonun bu hastalarda uygulanmaması gerektiği bildirilmiştir ${ }^{[23]}$. Ancak, TEN'de görülen anlamlı sıvı kayıplarının, sıvı alınımı yetersiz olduğunda hipovolemi, akut tübüler nekroz ve şoka neden olduğu bildirilmektedir [23]. İdrar çıkışının 0,5-1 mL/kg/saat fizyolojik nokta olarak kabul edildiğini gösteren çalışmalar bulunmaktadir ${ }^{[24]}$. Olgumuzda YB takipleri sırasında hemodinamik parametreleri stabil tutularak, idrar çıkışı $1 \mathrm{~mL} /$ $\mathrm{kg} / \mathrm{saat}$ olacak şekilde sıvı resüsitasyonu planlandı.

TEN'li hastalarda hastane öncesi bakımın yanıklı hastalarınkine benzer olduğu ve hipotermik ortamda oksijen gereksinmesi artacağından $30-32^{\circ} \mathrm{C}^{\prime}$ lık bir ortam sağlanarak hipoterminin önlenmeye çalışılmaSı gerektiği belirtilmektedir [25]. Biz bu olguda izole oda ISIsını, $28-30^{\circ} \mathrm{C}$ olacak şekilde ayarladık. TEN'li hastalarda enerji gereksinimleri ve protein kayıpları önemli ve doku tamirinde gecikmeye neden olabildikleri bildirilmektedir ${ }^{[26]}$. Hastamıza yüksek proteinli besinler başladık. Albümin değerleri $30 \mathrm{mg} / \mathrm{dL}$ altına hiç inmedi. TEN'li olgularda mukozada deri değiştirme ve ödem sonucu solunum sıkıntısı görülebileceği ve bu durumda endotrakeal entübasyon ve ventilasyon gerekebileceği belirtilmektedir ${ }^{[27]}$. Ancak hastamızda invaziv yada non-invaziv ventilayon gereksinimi olmadı.

TEN'li olgularda sepsis veya stafilokokal haşlanmış deri sendromu kuşkusu yoksa antibiyotik profilaksisinin gerekli olmadığı belirtilmektedir ${ }^{[28]}$. Biz bu olgu$\mathrm{da}$, mevcut bulunan osteomiyelit tedavisi için antibiyotik başladık. 
TEN'in standart tedavisinde; immünomodülatör olarak plazmaferez, $\mathrm{n}$-asetil sisten, kortikosteroid, siklofosfamid, siklosporin, TNF- $\alpha$ inhibitörleri, talidomid ve IVIg'ı da kapsayan geniş tedavi spektrumun etkili olduğu kanıtlanmıştır ${ }^{[29]}$. Tartışmalı olmakla birlikte, TEN başlangıç fazında T hücre aktivasyonunu inhibe eden ve enflamasyonu azaltan glikokortikoidler önerilmektedir ${ }^{[6]}$. Bu nedenle hastamıza metil prednizoIon sodyum süksinat (prednol-L: 2x40 mg) 13 gün süreyle uygulandı; akabinde azaltılarak 17 . günde kesildi. Tedavinin olumlu etkileri görüldü ve kortikosteroidlerin yan etkilerine rastlanmadı. Hastaya fasfas ligandı aracılığı ile apopitosisi direkt inhibe eden IVIg tedavisi uygulandı.

TEN ile ilişkili yaraların debride edilip edilmeyeceği ile ilgili tartışma literatürde hâlen devam etmektedir [13]. TEN'deki deri lezyonları yaklaşık 2 hafta içinde iyileşmekte, ancak mukozal membran lezyonlarının iyileşmesi uzun sürmekte ve karakteristik yara izi kalmaktadır. Bizim hastamızda da bu spesifik izler tedaviye rağmen kaldı.

Günümüzde oluşum mekanizması tam olarak anlaşılamayan TEN'de ilaçların başlıca etken olduğu kabul edilmektedir. Bu hastaların sürveyans kültürlerinin düzenli alınarak uygun antibiyoterapi ile takibi, tedavinin esasını oluşturmaktadır [30].

\section{SONUÇ}

Nadir görülen bir hastalık olan TEN'de ilaçların başlıca sorumlu olduğu bilinmektedir. Bu hastaların YB'de izole odada multidisipliner bir şekilde izlenmesi; minimal invaziv yaklaşım, uygun tedavi seçenekleri ile yönetilmesi gerekmektedir.

\section{KAYNAKLAR}

1. Assier H, Bastuji-Garin S, Revuz J, Roujeau JC. Erythema multiforme with mucous membrane involvement and Stevens- Johnson syndrome are clinically different disorders with distinct causes. Arch Dermatol. 1995;131:539-43.

2. Bastuji-Garin S, Rzany B, Stern RS, Shear NH, Naldi L,
Roujeau JC. Clinical classification of cases of toxic epidermal necrolysis, Stevens-Johnson syndrome, and erythema multiforme. Arch Dermatol. 1993;129:92-6.

3. Alpsoy E: Stevens Johnson sendromu ve toksik epidermal nekrolizis. Pediyatrik Dermatoloji. Ed. Tüzün $Y$, Kotoğyan A, Serdaroğlu $S$, Çokuğraş $H$, Tüzün $B$, Mat MC. İstanbul, Nobel Tıp Kitabevleri, 2005;389-95.

4. Roujeau JC, Chosidow O, Saiag P, Guillaume JC. Toxic epidermalnecrolysis (Lyell syndrome). J Am Acad Dermatol. 1990;23:1039-58.

5. Borchers AT, Lee JL, Naguwa SM, et al. Stevens-Johnson syndromeand toxic epidermal necrolysis. Autoimmun Rev. 2008;7:598-605.

6. Dicle O, Yılmaz E, Alpsoy E. Stevens-Johnson Sendromu ve toksik epidermal nekroliz: Retrospektif bir değerlendirme. Türkderm 2009;43:15-20.

7. Roujeau JC. Drug-induced toxic epidermal necrolysis. II. Current aspects. Clin Dermatol. 1993;11:493-500.

8. Ghislain PD, Roujeau JC. Treatment of severe drug reactions: Stevens-Johnson syndrome, toxic epidermal necrolysis and hypersensitivity syndrome. Dermatol Online J. 2002;8:5.

9. Bastuji-Garin S, Fouchard N, Berocchi $M$, et al. SCORTEN: a severity of illness score for toxic epidermal necrolysis. J Invest Dermatol. 2000;115:149-53.

10. Westly ED, Wechsler HL. Toxic epidermal necrolysis: granulocytic leukopenia as a prognostic indicator. Arch Dermatol. 1984;120:721-6.

11. Engelhardt SL, Schurr MJ, Helgerson RB. Toxic epidermal necrolysis: an analysis of referral patterns and steroid usage. J Burn Care Rehabil. 1997;18:520-4.

12. Guegan S, Bastuji-Garin S, Poszepczynska-Guigne' E, et al. Performance of the SCORTEN during the first five days of hospitalization to predict the prognosis of epidermal necrolysis. J Invest Dermatol. 2006;126:272-6.

13. Garcia-Doval I, LeCleach L, Bocquet $H$, Otero XL, Roujeau JC. Toxic epidermal necrolysis and StevensJohnson syndrome: does early withdrawal of causative drugs decrease the risk of death? Arch Dermatol 2000;136:323-7.

14. Revuz J, Penso D, Roujeau J-C, et al. Toxic epidermal necrolysis: clinical findings and prognosis factors in 87 patients. Arch Dermatol. 1987;123:1160-5.

15. Chave TA, Mortimer NJ, Sladden MJ, Hall AP, Hutchinson PE. Toxic epidermal necrolysis: current evidence, practical management and future directions. Br J Dermatol. 2005;153:241-53.

16. Schneck J, Fagot JP, Sekula P, et al. Effects of treatment on the mortality of Stevens-Johnson syndrome and toxic epidermal necrolysis: a retrospective study on patients included in the prospective EuroSCAR study. J Am Acad Dermatol. 2008;58:33-40.

17. Kardaun SH, Jonkman MF. Dexamethasone pulse the- 
rapy for Stevens-Johnson syndrome/toxic epidermal necrolysis. Acta Derm Venereol. 2007;87:144-8.

18. Yeung CK, Lam LK, Chan HH. The timing of intravenous immunoglobulin therapy in Stevens-Johnson syndrome and toxic epidermal necrolysis. Clin Exp Dermatol. 2005;30:600-2.

19. Mittmann N, Chan B, Knowles S, et al. Intravenous immunoglobulin use in patients with toxic epidermal necrolysis and Stevens-Johnson syndrome. Am J Clin Dermatol. 2006;7:359-68.

20. Schopf E, Stuhmer A, Rzany B, Victor N, Zentgraf R, Kapp JF. Toxic epidermal necrolysis and StevensJohnson syndrome. An epidemiologic study from West Germany. Arch Dermatol. 1991;127:839-42.

21. Akman A, Alpsoy E. Eritema multiforme, StevenJohnson sendromu ve toksik epidermal nekroliz (Lyell Sendromu). Türkiye Klinikleri J Surg Med Sci. 2006;2:615.

22. Struck MF, Hilbert $P$, Mockenhaupt $M$, et al. Severe cutaneous adverse reactions: emergency approach to non-burn epidermolytic syndromes. Intensive Care Med. 2010;36:22-32.

23. Endorf FW, Cancio LC, Gibran NS. Toxic epidermal necrolysis clinical guidelines. J Burn Care Res. 2008;29:706-
12.

24. Keskin Ö, Yıldırım i, Kalemoğlu M ve ark. Naproksen sodyum kullanımı sonucu gelişen toksik epidermal nekroliz olgusu. Nobel Med. 2005;1:28-31.

25. Endorf FW, Cancio LC, Gibran NS. Toxic epidermal necrolysis clinical guidelines. J Burn Care Res. 2008;29:70612.

26. Abood GJ, Nickoloff BJ, Gamelli RL. Treatment strategies in toxic epidermal necrolysis syndrome: where are we at? J Burn Care Res. 2008;29:269-76.

27. Nagy N, McGrath JA. Blistering skin diseases: a bridge between dermatopathology and molecular biology. Histopathology 2010;56:91-9.

28. Posadas SJ, Padial A, Torres MJ, et al. Delayed reactions to drugs show levels of perforin, granzyme $B$, and Fas- $\mathrm{L}$ to be related to disease severity. J Allergy Clin Immunol. 2002;109:155-61.

29. Yavuz C, Gürgey E. Toksik epidermal nekrozda tedavi yaklaşımları. Türkiye Klinikleri Dermatol. 2006;16:5968.

30. Kuzucuoğlu T, Özay HY. Toksik epidermal nekrolizli olgunun yoğun bakım yönetimi. Turk J Dermatol. 2018;12:187-90. 